\title{
Analysis And Prediction Of Fundamental Amplitude Of The Running Transformer
}

\author{
Zhan Zhao ${ }^{1, \text { a }}$ \\ ${ }^{1}$ North China Electric Power University, Baoding, Hebei, China \\ a1353866708@qq.com
}

Keywords: Condition monitoring, vibration analysis, in-service grid transformer.

\begin{abstract}
In this paper, a new model developed to estimate transformer vibration is presented. The model contains three parameters-current, voltage and temperature, which can be easily measured. Also, the vibration theory for transformers was analyzed, a six-channel vibration measurement system is set up and the vibration signals are measured. The least-squares method was used to calculate the model parameters which are used as print parameters to predict the vibration amplitude. The model has been tested experimentally on a running transformer fitted with sensors. Comparing with other two predicting model, we find the new model is more accurate. The new model also needs more data from running transformers to improve it.
\end{abstract}

\section{Introduction}

Running transformer's vibration signal is an important parameter in diagnosing the fault of core and winding. Especially, the fundamental amplitude of the tank vibration signal is used in transformer faults-diagnosing.

Theory analysis gives the results [1] that: when the fundamental amplitude of the vibration signal is less than $10 \%$ comparing with the historical data, we can know the running transformer is in normal state; when the difference is from $10 \%$ to $20 \%$, there may exist big fault and we need to take care; when the difference is larger than $20 \%$, the running transformer should be took out and be examined and repaired.

To diagnose the fault of running transformers early, many predicting models have been put forward. Garcia analyzed how current, voltage and temperature affect the fundamental amplitude [1]. And a model which contains three parameters-current, voltage and temperature was analyzed. Fujian takes out a simplified model which ignored the affect of temperature [4]. Temperature was ignored for two reasons: the temperature changing is not serious and also to make the calculation easier. Ma put forward another predicting model [5] based on the theory analyzed above and the data from experiments. However, the models mentioned above are got mainly in the laboratory which lacks the support data from the running transformers. We analyzed the reliability of the model that Fujian and Ma put forward using the data from a healthy running transformer. The simulation results show the two models are not accurate enough. A new predicting model is put forward and the simulation result shows the predicting amplitude matches better.

\section{Establishment of the measure system}

The signal-taking equipment is shown in Fig.1.

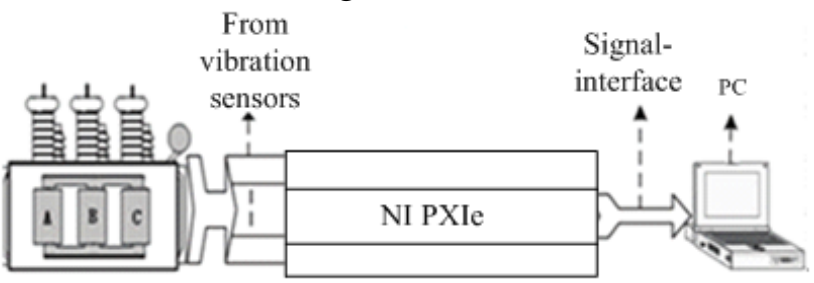

Fig. 1. Vibration measurement scheme for transformer 
Each of these vibration accelerative sensors has a sensitivity of $500 \mathrm{mv} / \mathrm{g}$, its scope is $10 \mathrm{~g}$ as well as the frequency response within $0.35 \sim 4000 \mathrm{~Hz}$. After the vibration signal was got from the sensors it will be processed by the NI PXIe equipment, then the digital vibration signals will be exported and processed by the personal computer (PC).

The recommended sensor positions are shown in Fig.2. Six points are used in our experiment, 3 at the high voltage bushing side and 3 at the low voltage bushing one, approximately equal distance from monitored elements. Points of sensor installation have not been chosen near manholes, pipelines or stiffening ribs.
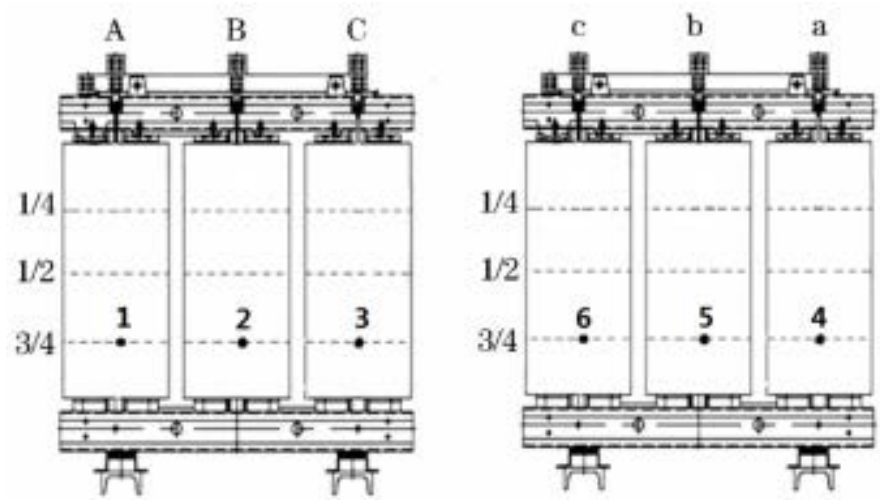

Fig. 2. Recommended sensor positions on the transformer surface

\section{Analysis of the transformer Vibration signal}

Transformer vibration theory. Transformer vibration is mainly caused by iron core and winding [1]. The magnetic expansion of the silicon steel sheet under the strong magnetic field leads to the iron core Vibration. The magnetostrictive properties of the silicon steel sheet are directly proportional to the square of magnetic induction strength. The amplitude of the vibration is proportional to the square of the excitation voltage. At the same time, the vibration signal of the iron core also contains high harmonic components due to the nonlinearity of the magnetostriction.

Winding vibration is caused by the electromagnetic force, which is proportional to the square of the winding current. There exist high order harmonic components due to the influence of nonlinear factors in the winding structure [2, 3].The vibration signal shown on the running transformers' surface is the combination of the two signals mentioned above. The fundamental component of $100 \mathrm{~Hz}$ in the vibration signal is mainly affected by the current and voltage.

Model 1. Ignoring the affection of the nonlinear parameters, the fundamental frequency component $V_{\text {tank, } 100 \mathrm{~Hz}}$ shown as follows ${ }^{[4]}$ :

$$
V_{\tan k, 100 \mathrm{~Hz}}=(\alpha+\beta \theta) I_{50 \mathrm{~Hz}}^{2}++(\gamma+\delta \theta) U_{50 \mathrm{~Hz}}^{2}
$$

Ignoring temperature's affection the simplified model ${ }^{[4]}$ is as follows:

$$
V_{\tan k, 100 \mathrm{~Hz}}^{2}=\alpha I_{50 \mathrm{~Hz}}^{4}+\beta U_{50 \mathrm{~Hz}}^{4}+\gamma I_{50 \mathrm{~Hz}}^{2} U_{50 \mathrm{~Hz}}^{2}
$$

The equation (2) can be solved using the least squares method, the procedure is as follows:

Assuming:

$$
\begin{aligned}
{[\alpha, \beta, \gamma] } & =A \\
{\left[I_{50 \mathrm{~Hz}}^{4}, U_{50 \mathrm{~Hz}}^{4}, I_{50 \mathrm{~Hz}}^{2} U_{50 \mathrm{~Hz}}^{2}\right]^{T} } & =X \\
{\left[V_{\tan k, 100 \mathrm{~Hz}}^{2}\right] } & =Y
\end{aligned}
$$


Formulation (2) equals to solve the equation:

$$
\|\bar{A} X-Y\|=\|A X-Y\|_{\min }
$$

Using the least-squares method we can get:

$$
\bar{A}=Y X^{T}\left(X X^{T}\right)^{-1}
$$

The simulation results are shown as below:

TABLE 1. Fault analysis in 'a' phrase of the low voltage side

\begin{tabular}{c|c}
\hline $\begin{array}{c}\text { Average } \\
\text { error }\left(\mathrm{ms}^{-2}\right)\end{array}$ & $\begin{array}{c}\text { root-mean-square error } \\
\left(\mathrm{ms}^{-2}\right)\end{array}$ \\
\hline 13.8316 & 0.2504 \\
\hline
\end{tabular}

TABLE 2. Fault analysis in 'a' phrase of the high voltage side

\begin{tabular}{c|c}
\hline $\begin{array}{c}\text { Average } \\
\text { error }\left(\mathrm{ms}^{-2}\right)\end{array}$ & $\begin{array}{c}\text { root-mean-square error } \\
\left(\mathrm{ms}^{-2}\right)\end{array}$ \\
\hline 19.8680 & 0.6695 \\
\hline
\end{tabular}

Using Model 1, the average relative error is large, which is not applicable in diagnosing transformer faults.

Model 2:

After a series of experiments and analysis, Ma put forward another model ${ }^{[5]}$ :

$$
V_{\tan k, 100 \mathrm{~Hz}}=(\alpha+\beta \theta) I_{50 \mathrm{~Hz}}^{2}+(\gamma+\delta \theta) U_{50 \mathrm{~Hz}}^{2}+\lambda \theta \mathrm{I}_{50 \mathrm{~Hz}}
$$

Ignoring oil temperature the simplified formulation shown as follows:

$$
V_{\tan k, 100 \mathrm{~Hz}}=\alpha I_{50 \mathrm{~Hz}}^{2}+\gamma U_{50 \mathrm{~Hz}}^{2}+\lambda I_{50 \mathrm{~Hz}}
$$

The least-squares method was used to solve the equation. Using the same data in Model 1, we can get the simulation result as follows:

TABLE 3. Fault analysis in 'a' phrase of the low voltage side

\begin{tabular}{c|c}
\hline $\begin{array}{c}\text { Average } \\
\text { error }\left(\mathrm{ms}^{-2}\right)\end{array}$ & $\begin{array}{c}\text { root-mean-square error } \\
\left(\mathrm{ms}^{-2}\right)\end{array}$ \\
\hline 8.9134 & 0.2538 \\
\hline
\end{tabular}

TABLE 4. Fault analysis in 'a' phrase of the high voltage side

\begin{tabular}{c|c}
\hline $\begin{array}{c}\text { Average } \\
\text { error }\left(\mathrm{ms}^{-2}\right)\end{array}$ & $\begin{array}{c}\text { root-mean-square error } \\
\left(\mathrm{ms}^{-2}\right)\end{array}$ \\
\hline 23.0601 & 0.7254 \\
\hline
\end{tabular}

When using Model 2, the predicted error decreases a lot but the average error is large thus it still not suitable in diagnosing transformer faults.

Model 3:

From the simulation results mentioned above we know the predicting models existed now are not accurate enough. In our experiments, the vibration sensors are fixed on the surface of the running transformers while not on the oil tank, the current has little affection to the vibration signal thus we put forward a new formulation:

$$
V_{\tan k, 100 \mathrm{~Hz}}=\alpha I_{50 \mathrm{~Hz}}^{2}+\beta U_{50 \mathrm{~Hz}}^{2}+\gamma \sqrt{\mathrm{I}_{50 \mathrm{~Hz}}}
$$


Using the same data as we used in Model 1, we can get the simulation result as follows:

TABLE 5. Fault analysis in 'a' phrase of the low voltage side

\begin{tabular}{c|c}
\hline $\begin{array}{c}\text { Average } \\
\text { error }\left(\mathrm{ms}^{-2}\right)\end{array}$ & $\begin{array}{c}\text { root-mean-square error } \\
\left(\mathrm{ms}^{-2}\right)\end{array}$ \\
\hline 8.8747 & 0.2528 \\
\hline
\end{tabular}

TABLE 6. Fault analysis in 'a' phrase of the high voltage side

\begin{tabular}{c|c}
\hline $\begin{array}{c}\text { Average } \\
\text { error }\left(\mathrm{ms}^{-2}\right)\end{array}$ & $\begin{array}{c}\text { root-mean-square error } \\
\left(\mathrm{ms}^{-2}\right)\end{array}$ \\
\hline 5.7961 & 0.1538 \\
\hline
\end{tabular}

From Table 5 and Table 6 we know when using Model 3 the average error and also the root-mean-square error decrease a lot. Which means in faults-diagnosing, Model 3 is more suitable.

\section{Conclusions}

In this paper, vibration monitoring has been proposed as a method to detect faults of running transformer. A model has been developed to predict vibrations based on measured data, taking current, voltage and temperature into account. Only the main component of vibration signal is used in the model, as higher harmonics are much lower and do not show a strong dependence with current. Comparing the model with the other two models we find the new model is more accurate. However the model was put forward when the transformer is in healthy state. It should be improved using more data from running transformers. This paper will accelerate the application of the fault-diagnosing methods based on vibration signal in online monitoring.

\section{References}

[1] ZHU Yeye.JI Shengchang.ZHANG Fan.LIU Yong.DONG Hongkui.CUI Zhigang.WU Jiawei Vibration Mechanism and Influence Factors in Power Transformers- JOURNAL OF XI'AN JIAOTONG UNIVERSITY 2015(6)

[2] Belén García, Juan Carlos Burgos, and Ángel Matías Alonso, "Transformer Tank Vibration Modeling as a Method of Detecting Winding Deformations - Part I: Theoretical Foundation ", IEEE Transactions on Power Delivery, Vol.21, No.1, pp. 157-163, 2006.

[3] Belén García, Juan Carlos Burgos, and Ángel Matías Alonso, "Transformer Tank Vibration Modeling as a Method of Detecting Winding Deformations-Part II: Experimental Verification ", IEEE Transactions on Power Delivery, Vol.21, No.1, pp. 164-169, 2006.

[4] Fujian. XU Jian. CHEN Keliang.WANG Fenghua. JIANG Yiming .JIN Zhijian On-line transformer monitoring based on vibration analysis-East China Electric Power 2009(7).

[5] MA Hongzhong. GENG Zhihui. CHEN Kai. WANG Chunning.LI Kai.LI Yong, " A New Fault Diagnosis Method for Power Transformer Winding Deformation Based on Vibration"-Automation of Electric Power Systems2013(8). 